\title{
Чувствительность пленок PbSnTe:In к тепловому излучению низкотемпературных (вплоть до $\mathrm{T}=60 \mathrm{~K})$ источников
}

\author{
А.Э. Климов ${ }^{1,2}$, В.А. Голяшов ${ }^{1,3}$, Д.В. Горшков ${ }^{1}$, Н.С. Пащин ${ }^{1}$, Г.Ю. Сидоров ${ }^{1}$, С.П. Супрун ${ }^{1}$, \\ В.Н. Шерстякова ${ }^{1}$, О.Е. Терещенко ${ }^{1,3}$ \\ ${ }^{1}$ Институт физики полупроводников им. А.В. Ржанова СО РАН, Новосибирск, \\ 630090, пр. Ак. Лаврентьева, 13 \\ тел: +7 (383) 330-7883, факс:+7 (383) 333-2771, эл. nочта: klimov@isp.nsc.ru \\ ${ }^{2}$ Новосибирский государственный технический университет, Новосибирск, \\ 630073, пр. Карла Маркса, 20 \\ ${ }^{3}$ Новосибирский государственный университет, Новосибирск, 630090, Пирогова, 1
}

DOI 10.34077/RCSP2021-39

$\mathrm{B}$ настоящее время интерес к узкозонному $\mathrm{Pb}_{1-\mathrm{x}} \mathrm{Sn}_{\mathrm{x}}$ Те обусловлен, прежде всего, наличием фазы топологического кристаллического изолятора (ТКИ) в области инверсии краев зоны проводимости и валентной зоны. Вблизи $T=4,2$ К фаза ТКИ реализуется в области $x>x_{\mathrm{inv}} \approx 0,35$. Формально $x_{\mathrm{inv}}$ соответствует $E_{\mathrm{g}}=0$. При $x \sim x_{\text {inv }}$ потенциально возможно получение $\mathrm{PbSnTe}$ со сколь угодно малой $E_{\mathrm{g}}$. Это является базой для создания фотодетекторов (ФД) на межзонных переходах не только для сверхдальнего ИК, но и терагерцового (ТГц) спектральных диапазонов. Известно также, что добавление индия с концентрацией (1-2) ат.\% позволяет на многие порядки снизить проводимость в $\mathrm{PbSnTe}: I n$ в определенной области $x$ с улучшением пороговых параметров ФД [1]. Значительное число публикаций подтверждает чувствительность PbSnTe в указанных диапазонах [1,2]. Однако прямое

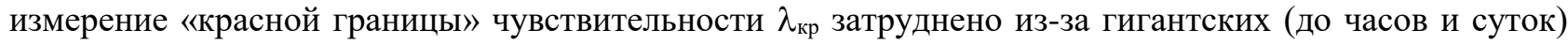
постоянных времени фотоответа $\tau_{\phi}$ при гелиевых температурах. Так, при типичном для спектральных измерений уровне фонового излучения сопротивление образцов и постоянные времени фотоответа снижаются, по сравнению с «темновыми», на многие порядки (до $10^{8}$ раз и более). Это может существенно менять $\lambda_{\text {кр }}$, особенно в случае, если чувствительность зависит от заселенности уровней в запрещенной зоне.

ФД ИК диапазона широко используются в системах формирования теплового изображения источника и «сцены». Их важнейшим параметром является не только температурное разрешение, но и

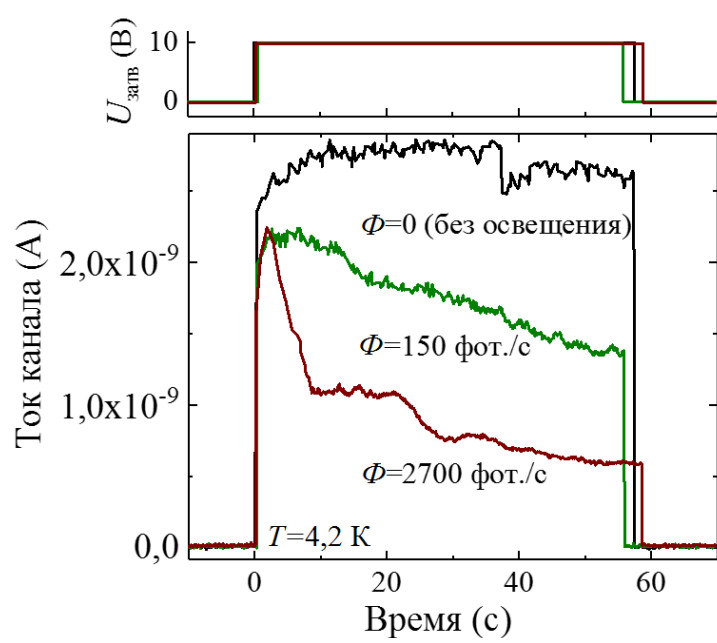

Зависимости затворного напряжения (вверху) и тока канала от времени при разных потоках квантов на МДП структуру. допустимая средняя температура «сцены». Очевидно, что чем больше $\lambda_{\text {кр }}$, тем меньшая температура «сцены» может регистрироваться. В работе представлены результаты прямых измерений параметров макетов детекторов с большими $\tau_{\phi}$ при $T=4,2$ К к излучению АЧТ с $T_{\text {Ачт }}<80 \mathrm{~K}$ в условиях сверхнизкого фонового потока. Подобные условия могут реализовываться, например, при наблюдении за удаленными объектами Солнечной системы. При $T_{\mathrm{AчT}}=70 \mathrm{~K}$ получено значение температурного разрешения $\Delta T<0,0007 \mathrm{~K}$, соответствующее интегральной обнаружительной способности по этому источнику $D^{*}>10^{14}$ см.ГЦ ${ }^{0} \cdot 5 \cdot \mathrm{BT}^{-1}$. Рассмотрены механизмы фоточувствительности, оценено значение $\lambda_{\text {кр }}$ и возможность управления $\tau_{\phi}$ в PbSnTe:In-фотодетекторах на основе впервые созданных МДП-структур с $\mathrm{Al}_{2} \mathrm{O}_{3}$ подзатворным диэлектриком. В качестве иллюстрации на рисунке показано изменение тока канала структуры этого типа под действием освещения в условиях малых потоков фотонов $\Phi$.

Работа выполнена при поддержке РФФИ (грант № 20-02-00324).

\section{Лuтература}

[1] Л.И. Рябова, Д.Р. Хохлов // УФН. 2014. Т.184, вып. 10. С. 1033-1044.

[2] A.N. Akimov et al. // J. Phys.: Conf. Series. 2018. V. 946, P. 012016. 